\title{
Coulisses
}

Revue de théâtre

15 | Hiver 1997

Varia

\section{La Querelle de L'École des femmes de Molière}

Mise en scène René Loyon

Bertrand Degott

\section{CpenEdition}

Journals

Édition électronique

URL : http://journals.openedition.org/coulisses/5034

DOI : $10.4000 /$ coulisses.5034

ISSN : 2546-9460

Éditeur

Presses universitaires de Franche-Comté

Édition imprimée

Date de publication : 1 janvier 1997

Pagination : 26-28

ISSN : $1150-594 X$

Référence électronique

Bertrand Degott, «La Querelle de L'École des femmes de Molière », Coulisses [En ligne], 15 | Hiver 1997, mis en ligne le 26 avril 2019, consulté le 10 décembre 2020. URL : http://journals.openedition.org/ coulisses/5034; DOI : https://doi.org/10.4000/coulisses.5034

Ce document a été généré automatiquement le 10 décembre 2020.

Coulisses 


\title{
La Querelle de L'École des femmes de Molière
}

\author{
Mise en scène René Loyon
}

Bertrand Degott

(au Nouveau Théâtre de Besançon, du 3 au 21 décembre 1996) ${ }^{1}$

1 L'École des femmes est la première grande comédie de Molière. Lorsque Molière écrit ensuite coup sur coup La Critique et L'Impromptu, c'est en réponse aux attaques et aux cabales des contemporains contre sa pièce : acteurs de l'Hôtel de Bourgogne, auteurs jaloux de son succès, esprits chagrins que la nouveauté encore et toujours rend maussades... Soucieux de faire (re)découvrir et partager cette aventure théâtrale dans son intégralité, René Loyon décline les trois pièces, par exemple ce samedi 23 novembre, tandis qu'il neige dehors à lourds flocons. Et c'est - par moments - un réel bonheur.

Bonheur, d'abord, de Serge Maggiani, Arnolphe puis Molière magistral, amené en l'occurrence à se composer un masque à double épaisseur; s'il donne au Molière de L'Impromptu une grande humanité, on la perçoit déjà dans son jeu de L'École. Aussi, bien qu'on les sache inutiles, condamnés par les lois du genre, les efforts d'Arnolphe ne nous paraissent-ils jamais exclusivement dérisoires ou comiques. Le dénouement, comme plus tard celui de L'Avare, du Misanthrope ou bien de Dom Juan, ne nous satisfait pas pleinement : ne consacre-t-il pas en effet la victoire du consensus et des médiocres - du raisonnant Chrysalde jusqu'à cet accouplage banal d'une oie blanche et d'un jeune coq-, contre cet homme qui tâche d'édifier son bonheur, malgré son âge, en dépit d'une noblesse de fortune et d'une bile alternativement noire et jaune, à l'écart du monde et de ses convenances? La grande comédie de Molière donne à celui même qu'elle traite en ridicule une épaisseur d'âme telle qu'elle nous force à la compassion ; elle nous rappelle aussi que Molière ne vint à la comédie que pour avoir échoué sur la scène tragique. Ce soir, lorsque Arnolphe s'assied à grand peine dans le fauteuil de velours, et plus encore quand Molière vient sur le devant de la scène pour parler de son théâtre, quelque chose d'inconnu et d'immense saisit la salle, et c'est pour un instant l'esprit de Molière qui fait parler le comédien Maggiani. 
2 «Dans cette comédie-ci, il ne se passe point d'actions, et tout consiste en des récits que vient faire ou Horace ou Agnès. » Ainsi parle Lysidas dans La Critique : difficile de lui donner tort, L'École des femmes nous ennuie par endroits. Aussi l'entrée d'Alain et Georgette fait-elle chaque fois souffler une divertissante bise d'agitation et de folie sur cette scène où si peu change hormis l'éclairage du temps qui s'écoule. Céline Châtelain, méconnaissable sous son bonnet, bourre sa Georgette d'énergie et de santé, se tordant jusqu'en ses extrémités, souffletant son compère ou éclatant telle un pétard: on a grand plaisir à la retrouver ensuite dans la sautillante Mademoiselle de Brie, et les regards qu'elle coule à Du Croisy lorsqu'il joue Lysidas mériteraient à eux seuls qu'on aille revoir L'Impromptu de Versailles; Claude Monnoyeur (c'est à lui justement que ces regards s'adressent) nous offre aussi des compositions étonnantes par leur diversité, notamment ce marquis de La Critique dont il fait exploser la fatuité. On ne voudrait pas oublier ici Estelle Aubriot (Climène-Mademoiselle du Parc), perruquée tout en hauteur et en couleur, maquillée à outrance, à la fois mécanique et subtile dans son rôle de «façonnière ».

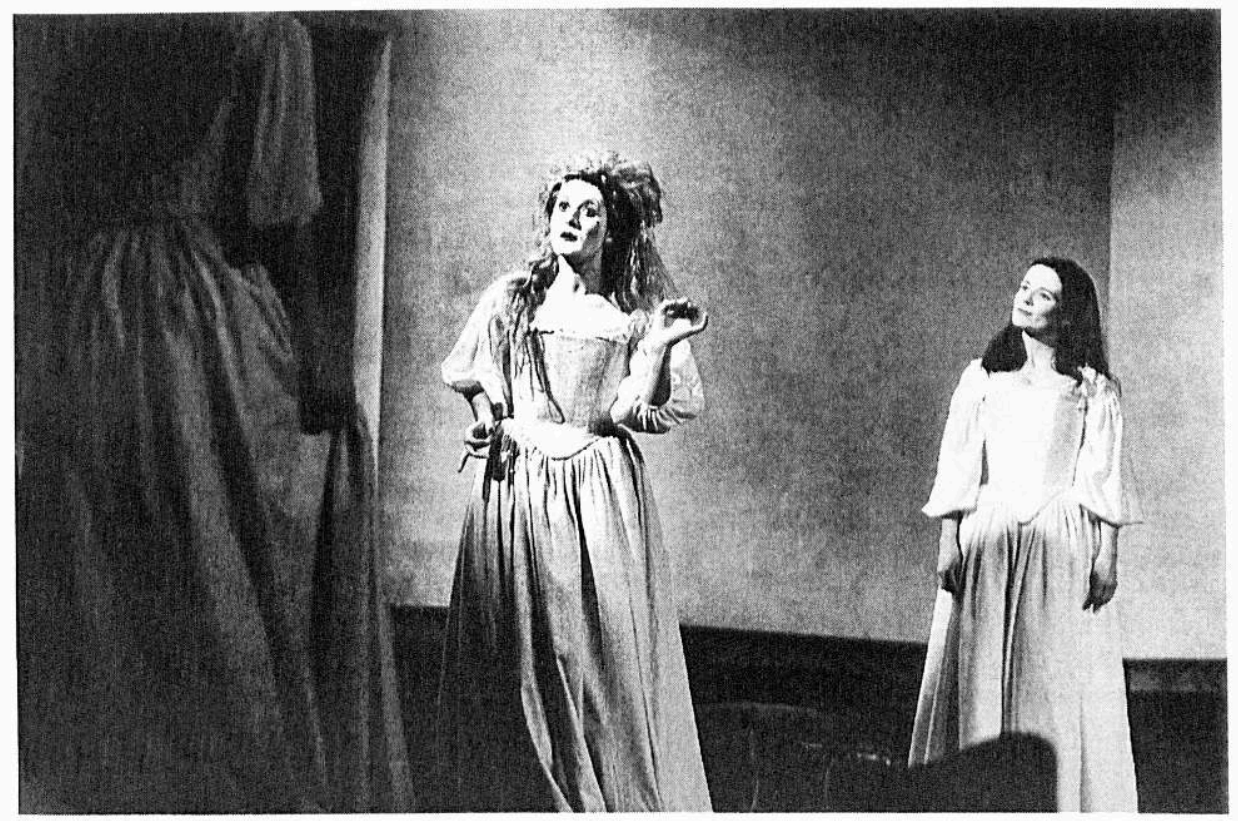

Photo Florian Tiedje

On s'étonne alors de ne garder souvenir, en fait de mise en scène, que de ces numéros d'acteurs, quand celle-ci devait les utiliser au profit d'un ensemble plus vaste, d'une construction plus ambitieuse. René Loyon se met très respectueusement au service du texte de Molière, ce qui est déjà beaucoup, mais sans prendre de réels risques : était-il vraiment impensable, par exemple, à l'occasion de cette "querelle», que l'on reconstitue la distribution du vivant de Molière? car on est déçu de ne pas y retrouver certaines des allusions que voyaient les contemporains (tel ce Détestable morbleu! détestable! tarte à la crème! qui assure la continuité). On s'interroge peut-être aussi sur le choix du blanc pour les costumes de La Critique, sur l'intérêt encore d'y maintenir au mépris du rythme de la pièce cette entrée en scène désastreuse du valet maladroit, enfin sur la présence de Molière côté cour qui s'éclipse pour revenir de la salle au moment de L'Impromptu. 
4 Et puis, pourquoi personne ne dit-il à Muriel Racine de faire quelque chose de ses mains? Quant au décor, entre les deux parties de la soirée, peu de choses ont changé sur le plateau: pour L'Ecole des femmes, une branche dans l'encoignure côté jardin matérialise un décor d'extérieur ; pour La Critique et L'Impromptu, pièces d'intérieur, la branche est passée de l'autre côté de la fenêtre. Cela peut suffire à évoquer de quelle nature est la distance entre ces pièces, entre la grande comédie et ses commentaires (au premier et au second degré).

5 Les meilleurs moments de la soirée nous ont fait oublier jusqu'à la neige. On la retrouvera au dehors lorsque tout sera fini, mais les pâles fantômes de Molière et de ses acteurs nous accompagneront encore un moment. Plus longtemps, il faut bien le dire, que la mise en scène de René Loyon. A l'évidence, le théâtre reste un art vivant, malgré les tentatives que poursuivent à l'écran les grands fossoyeurs de l'intelligence.

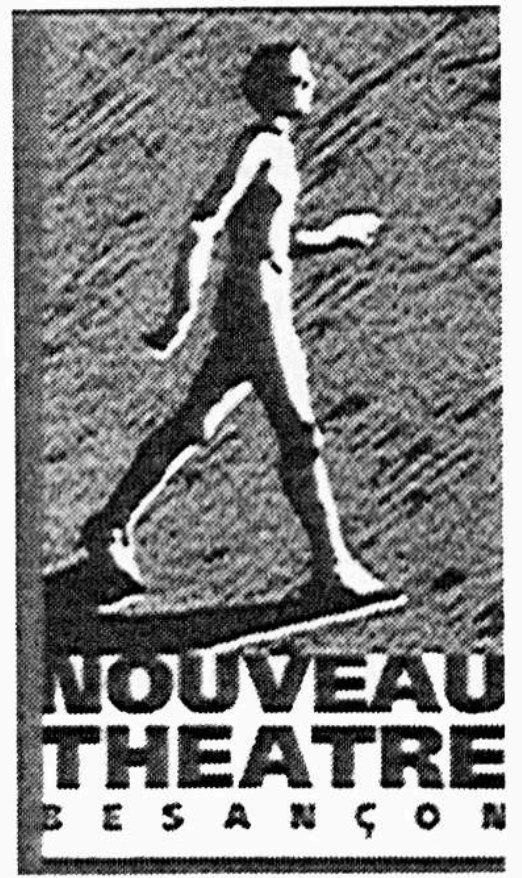

\section{NOTES}

1. La saison 97 nous annonce d'autres mises en scènes: Pierre Louis, le 28 Mars à L'Arche de Bethoncourt, et les 9 et 10 Avril au CAHD, à Pontarlier.

Daniel Benoin, du 26 au 28 Mars au Théâtre Granit - Belfort 